\title{
Bending fatigue strength design method for machine components with complex geometries
}

\author{
Gang Deng, Tsutomu Nakanishi \\ Department of Mechanical Design Systems Engineering, Faculty of Engineering, University of Miyazaki, \\ 1-1 Gakuen Kibanadai-nishi, Miyazaki Shi, Miyazaki 889-2192, Japan \\ t0d114u@cc.miyazaki-u.ac.jp,t0d115u@cc.miyazaki-u.ac.jp
}

\begin{abstract}
The purpose of this study is to devise a bending fatigue strength evaluation method that can be widely used for any machine component under the consideration that bending fatigue breakage depends on the initiation of a surface fatigue crack, namely, the conditions for the initiation of a fatigue crack can be used as the criteria for bending fatigue strength design. The specially designed and manufactured three-point bending specimens with crowned round notches are used in bending fatigue experiments. The obtained bending fatigue strengths are expressed as the maximum actual stress at the critical point, which increases with decreasing notch radius. Considering the effects of the stress distribution on the bending fatigue strength, we present a method for estimating the tension fatigue strength of a smooth specimen, which is shape-independent fatigue strength and can be applied to bending fatigue strength design for machine components with complex geometries.
\end{abstract}

KEYwORDS. Bending fatigue strength; Fatigue crack initiation; Stress distribution; Shape-independent fatigue strength

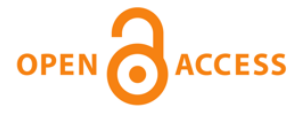

Citation: Deng, G., Nakanishi, T., Bending fatigue strength design method for the machine components with complex geometries, Frattura ed Integrità Strutturale, 46 (2018) 45-53.

Received: 07.03.2018

Accepted: 15.04.2018

Published: 01.10.2018.

Copyright: (C) 2018 This is an open access article under the terms of the CC-BY 4.0, which permits unrestricted use, distribution, and reproduction in any medium, provided the original author and source are credited.

\section{INTRODUCTION}

A lthough the bending fatigue strength design of machine elements such as gears and shafts can be performed in accordance with design documents, there are still no practical methods applicable to other machine elements with different shapes. Many accidents have occurred owing to the fatigue of machine component with a wide range of geometries, such as the fatigue breakage of the tire hub of heavy-duty truck. Since the bending fatigue strength is expressed as the nominal stress calculated on the basis of material mechanics with many simplifications of the shapes and loading conditions, it varies even among machine components with the same material qualities [1,2]. Consequently, the bending fatigue strength design of machine components with a wide range of geometries cannot be performed using the methods shown in the design documents. To avoid accidents owing to the bending fatigue breakage of machine components, a general bending fatigue strength evaluation method applicable to a wide range of geometries is required.

Bending fatigue breakage is a result of surface crack initiation and propagation. Nisitani [3] and Ohba [4] indicated that a fatigue crack will not stop growing unless an extremely high stress concentration occurs at the critical point where the fatigue crack is initiated. Deng [5] and Hammouda [6] showed that the fatigue initiation life accounts for a large proportion of the 
fatigue life when the stress level is near to the bending fatigue strength. On the basis of fracture mechanics and the research of Nisitani [7], the mechanical factors determining fatigue breakage are not only the actual stress but also its distribution. At present, the actual stress and its distribution can be easily and accurately calculated for any machine component, but they have not yet been used in bending fatigue strength design. To develop a general bending fatigue strength evaluation method applicable to machine components with a wide range of geometries, the actual stress and its distribution should be considered as very important factors.

Nisitani $[3,7]$ and Tanaka [8] carried out many studies on bending fatigue strength evaluation, where the strengths were defined on the basis of the criteria of crack initiation or the arrest of crack propagation, and they presented a method of obtaining the fatigue strength from the threshold stress intensity factor. Because of the difficulty of determining the threshold stress intensity factor and because fatigue strength design allowing the existence of a non-propagating crack is unrealistic considering safety, their method is not practically used. Kato [9] introduced the use of the initial crack length to evaluate the qualities of a surface and presented a fatigue life simulation method under the assumption that the progress of fatigue involves only the progress of crack propagation. However, many problems remain in deciding the initial crack length, which is very sensitive to the simulation conditions.

The purpose of this study is to search for a general method for bending fatigue strength design applicable to machine components with a wide range of geometries that considers the effects of the actual stress and its distribution on fatigue crack initiation. As the first stage of this study, three-point bending specimens with notches of different shapes are used to obtain bending fatigue limit stresses, which are expressed as the maximum stress at the critical point on the notch surface, and an approach to estimating the tension fatigue strength of a smooth specimen is presented, which will be the basic material property used in general bending fatigue design.

\section{CONSIDERATION OF THE STRENGTH AND CRITERIA FOR BENDING FATIGUE}

\section{Bending fatigue limit stress and bending fatigue load capacity}

hanges in the shape of a machine element, such as the introduction of a notch, a hole, or a corner, will decrease the bending fatigue strength expressed by the nominal stress as, stated in fatigue design documents, and this phenomenon is evaluated using the fatigue stress concentration factor. However, if the actual stress at the critical point is used in fatigue strength evaluation, the limit stress for bending fatigue breakage will increase owing to the existence of a feature such as a notch or stress concentration [10]. To avoid introducing the misunderstanding that the stress concentration increases the fatigue strength of a machine element, the bending fatigue limit stress and bending load capacity are used to indicate the maximum actual stress and the bending load without fatigue breakage, respectively. Thus, the stress concentration due to the introduction of such notches, holes, or corners will increase the bending fatigue limit stress but decrease the bending load capacity.

\section{Factors affecting the initiation of a fatigue crack}

Many studies have shown that the fatigue crack initiation life accounts for a large proportion of the fatigue life, particularly when the stress level is close to the fatigue strength, and that a fatigue crack will not stop growing unless the shape around the critical point is very sharp [3]. Thus, fatigue crack initiation may be a sufficient condition for bending fatigue breakage, which means that whether or not bending fatigue breakage occurs depends on the initiation of a surface fatigue crack, and the criteria for the initiation of a fatigue crack can be used for bending fatigue strength design.

Fatigue crack initiation and growth depend on the stress intensity factor in fracture mechanics [11,12]. On the basis of linear elastic fracture mechanics, the stress intensity factor is related to the potential energy release rate and elastic properties of the material. The potential energy release rate is also strongly related to the distribution of the stress around the tip of the crack or the critical point. Consequently, the initiation of a fatigue crack depends not only on the actual surface stress but also on its distribution. Fig. 1 shows images of the stress distributions around notches with small and large radii that have sharp and gentle stress gradients, respectively. The change in the potential energy release rate owing to the initiation is related to the hatched area. If the threshold value of the potential energy release rate for fatigue crack initiation is constant $\left(e_{1}=e_{2}\right)$, a larger surface stress with a high gradient will exist on the surface of the notch with the smaller radius, and a smaller stress with a gentle stress gradient will exist on the surface of the notch with the larger radius. This is considered to be the main reason why the fatigue strength expressed by the actual stress at the critical point varies for different shapes.

In the evaluation of the effect of the stress distribution on bending fatigue crack initiation, we think that only a very small region around the critical point should be considered since the length of the initiated crack is only micrometer order; and on the basis of the linear-elastic analysis results of stress distributions in depth direction for the typical shapes such as that 
shown in Fig. 1 as well as our test specimens, the stress distribution form the critical point can in practice be approximated by a linear distribution under several tens of micrometer. Thus, the stress gradient at the critical point can be used to characterize the stress distribution. In this research, three directions at the critical point are considered as shown in Fig. 2. However, if the shape around the critical point is not sharply notched and the critical point is located at the bottom of the notch, owing to the symmetrical shape very close to the notch bottom, the stress gradients along the $y$ and $z$ directions on the surface will be zero. Thus, as the first step, the effect of the stress distribution on bending fatigue crack initiation is evaluated using the stress gradient in the depth direction.

In addition, if we use the requirement for surface fatigue crack initiation as the criteria for bending fatigue breakage, our noticing spot in fatigue design will be a very small area around the critical point instead of the geometry of the machine component. Fig. 3 shows a magnified view around initiated cracks (microcracks) of 10, 5, and $1 \mu \mathrm{m}$ on an edge with a radius of $1 \mathrm{~mm}$. Since the just-initiated fatigue crack is extremely short compared the dimensions around the critical point, except for in the case of a sharp notch, the geometries of the critical points of many machine components can be simplified as a semi-infinite surface in comparison with the length of the initiated fatigue crack. Thus, only the maximum stress at the critical point and the stress gradient should be considered in the bending strength design for machine components with a wide range of geometries.

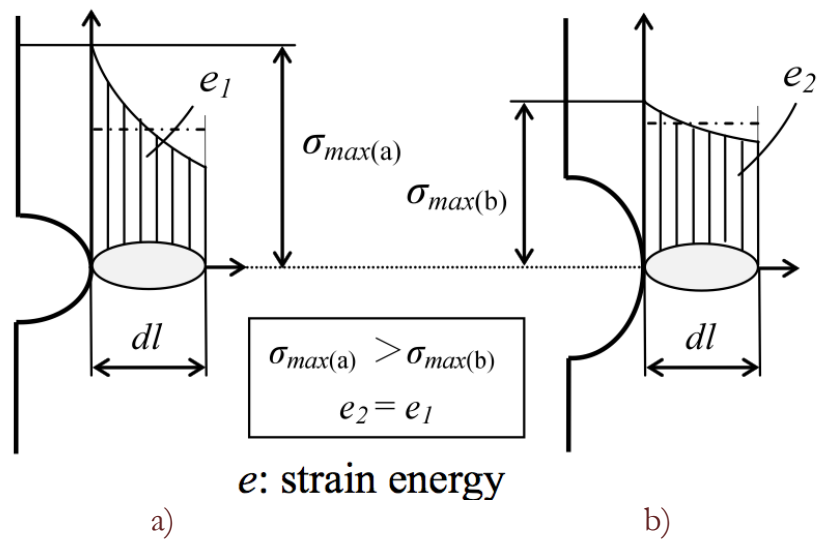

Figure 1: Different stress distributions for an identical potential energy release. a) Sharp stress gradient; b) Gentle stress gradient.

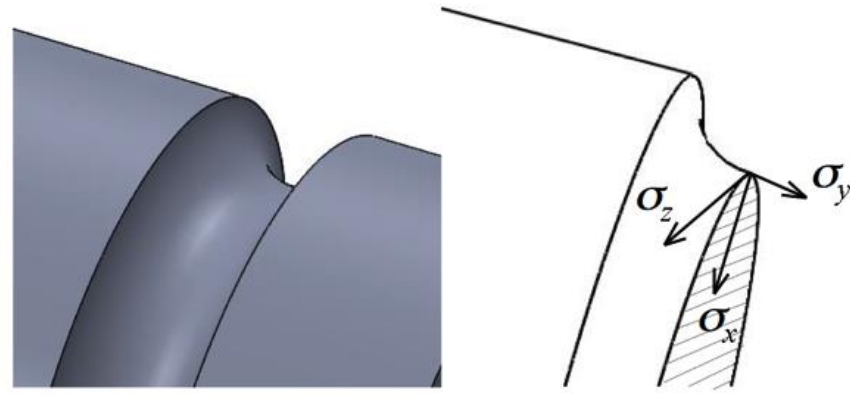

Figure 2: Stress directions at the critical point.

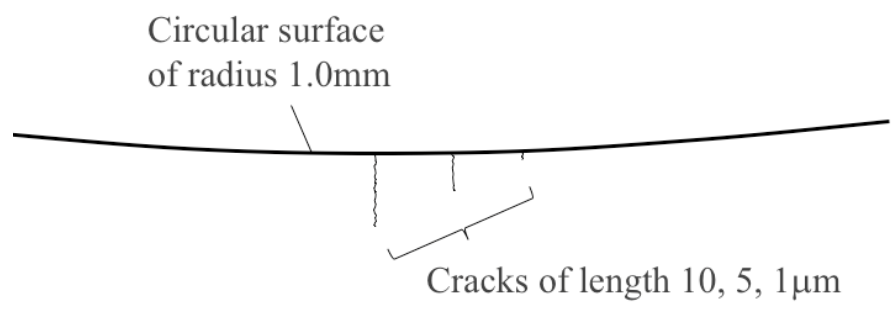

Figure 3: Microcrack on a circular surface of radius $1.0 \mathrm{~mm}$.

\section{THREE-POINT BENDING FATIGUE TEST AND SPECIMENS}

T o investigate the effects of the stress distribution on the bending fatigue limit stress, three-point bending specimens were used in fatigue tests on a hydroelectric servo pulsating fatigue test rig. The loading frequency was $30 \mathrm{~Hz}$ and the load ratio $\left(P_{\min } / P_{\max }\right)$ was about 0.05 . The loading method and a view of a specimen in the test rig are shown in Fig. 4. In general, standard three-point bending specimens are used to investigate fatigue crack growth characteristics, where $\mathrm{U}$ notches or $\mathrm{V}$ notches are introduced so that a crack easily initiates. However, in this research, the three-point bending specimens are used to estimate the fatigue strength determined by the crack initiation and crack propagation process. To 
prevent crack initiation from the sharp corner of a notch and consider the situation that a crack initiates from the fillet of a machine element, notches with a crowned round shape are introduced in the specimens. The dimensions of the specimens are shown in Fig. 5; the length, thickness, and height of each specimen were 100, 10, and 20mm, respectively, and the supporting span in the test was $80 \mathrm{~mm}$. The depth of the notch $T$ was about $5 \mathrm{~mm}$ and the crowning radius $R$ was from $5.8 \mathrm{~mm}$ to $6.2 \mathrm{~mm}$. The stress distributions around the notches were changed by changing the radius of the round notch to $2.5,3.0,4.0,5.0$, and $6.0 \mathrm{~mm}$.

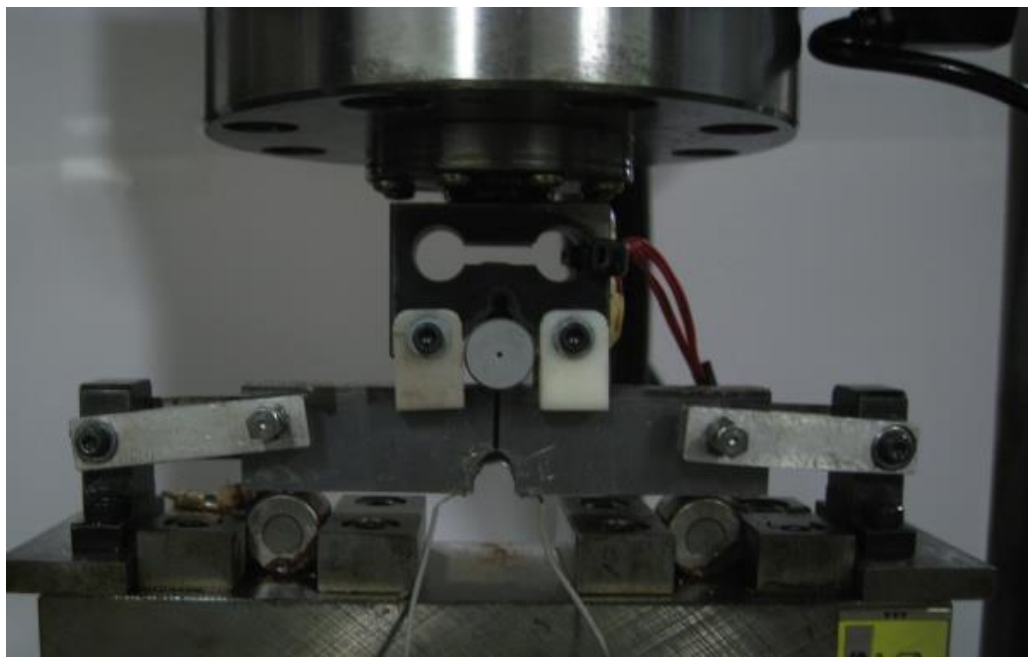

Figure 4: Three-point fatigue test rig.

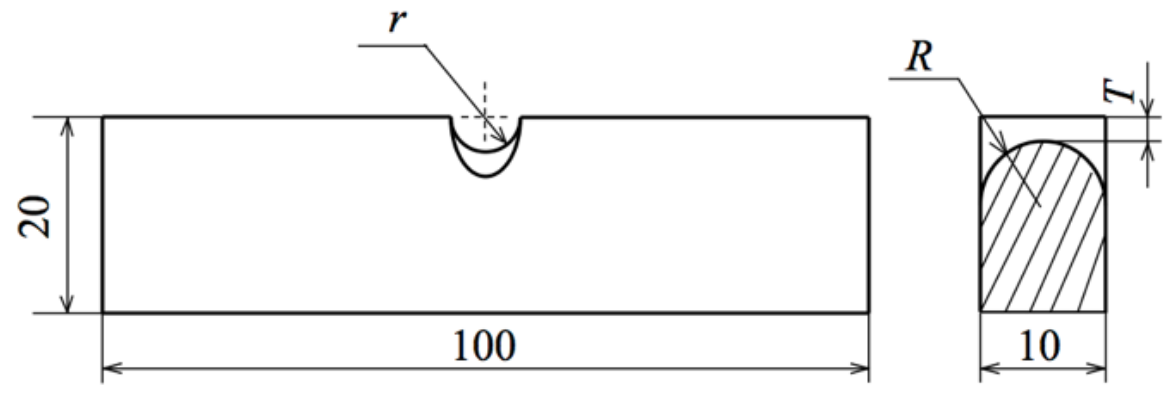

Figure 5: Three-point bending specimen.

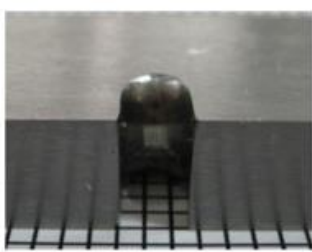

$r=2.5 \mathrm{~mm}$

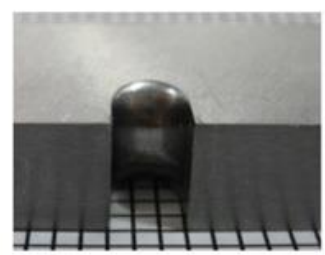

$r=3.0 \mathrm{~mm}$

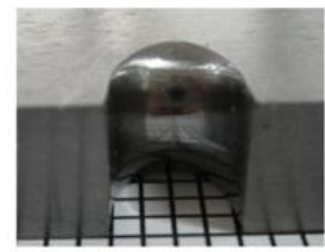

$r=4.0 \mathrm{~mm}$

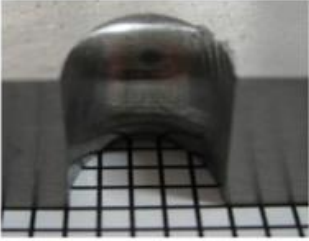

$r=5.0 \mathrm{~mm}$

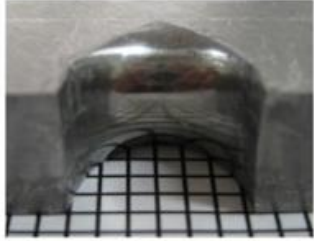

$r=6.0 \mathrm{~mm}$
$5 \mathrm{~mm}$

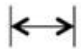

Figure 6: Notch shapes and surface features.

The specimens were made of carbon steel (S55C JIS, C0.55\%, Si0.25\%, Mn0.75\%) from a bar of $110 \mathrm{~mm}$ diameter. Since the purpose of this research is to estimate the shape-independent fatigue strength of a material, the surfaces were treated to 
minimize the effects of surface roughness and work hardening around the notches, which influence the crack initiation process, as follows. After the machining of the notch, the notch surfaces were mirror-polished using abrasive papers, and then vacuum normalization was carried out to minimize the effects of machining on the notch surface. The hardness of the specimens was approximately $219 \mathrm{HBS}\left(\sigma_{0.2}>390 \mathrm{MPa}\right)$. The very thin oxide layer that formed during the normalization was removed using a \#2000 emery paper. The calculated average roughness $R_{a}$ and maximum height roughness $R_{y}$ of the specimens were approximately $0.03 \mu \mathrm{mR} a$ and $0.15 \mu \mathrm{mR} y$, respectively. Photographs of the final notch surfaces are shown in Fig. 6, and the realization of mirror-polished notch surfaces was confirmed.

\section{BENDING FATIGUE LIMIT STRESSES AND BENDING LOAD CAPACITIES}

7 he staircase method recommended by Little [13] is used to estimate the bending fatigue strength evaluated by the actual stress at the critical point. Distinguishing the bending fatigue strength evaluated by the nominal stress from that evaluated by the actual stress at the critical point, the bending fatigue limit stress is used in this research. On the basis of Little's method, the bending fatigue limit stress $\sigma_{w}$ was estimated as $\sigma_{0}+\Delta \cdot \sigma_{d}$, where $\sigma_{0}$ is the stress level for the first specimen, $\Delta$ is a coefficient depending on the permutation of fatigue test results, and $\sigma_{d}$ is the increment of the stress level in the fatigue tests. The permutations of the fatigue test results are shown by $\mathrm{O}$ and $\mathrm{X}$, where $\mathrm{O}$ denotes that fatigue breakage did not occur up to $1 \times 10^{7}$ load cycles and $\mathbf{X}$ denotes that fatigue breakage occurred before $1 \times 10^{7}$ load cycles. Five fatigue tests were performed for each type of specimen. The stress level $\sigma_{0}$ for the first specimen was determined by pretests. The increment of the stress level $\sigma_{d}$ in the staircase method was set to $30 \mathrm{MPa}$, referring to the standard deviation in the work of Jeong [14]. A sinusoidal pulsating load was applied to each specimen. The maximum actual stress (the maximum principal stress $\sigma_{l}$ ) at the critical point of the notch in the length direction of the specimen, calculated using FEM analysis software, was used to represent the stress level and the bending fatigue limit stress.

\begin{tabular}{|c|c|c|c|c|}
\hline $\begin{array}{l}\text { Notch } \\
\text { radius }\end{array}$ & \multicolumn{2}{|c|}{ Experimental results } & $\begin{array}{c}\text { Coefficient } \\
\Delta^{[13]}\end{array}$ & $\begin{array}{l}\text { Bending fatigue } \\
\text { limit stress }\end{array}$ \\
\hline 2.5 & $\begin{array}{l}830 \mathrm{MPa} \\
800 \mathrm{MPa} \\
770 \mathrm{MPa}\end{array}$ & $0^{x} \times 0^{x}$ & -0.42 & $\begin{array}{l}800-0.42 \times 30 \\
=787(\mathrm{MPa})\end{array}$ \\
\hline 3.0 & $\begin{array}{l}800 \mathrm{MPa} \\
770 \mathrm{MPa} \\
740 \mathrm{MPa}\end{array}$ & $\mathrm{a}^{\times} \mathrm{x}^{\times} \times 0$ & 0.82 & $\begin{array}{l}740+0.82 \times 30 \\
=765(\mathrm{MPa})\end{array}$ \\
\hline 4.0 & $\begin{array}{l}770 \mathrm{MPa} \\
740 \mathrm{MPa} \\
710 \mathrm{MPa}\end{array}$ & $0^{\times} \times 0$ & 0.42 & $\begin{array}{l}740+0.42 \times 30 \\
=753(\mathrm{MPa})\end{array}$ \\
\hline 5.0 & $\begin{array}{l}770 \mathrm{MPa} \\
740 \mathrm{MPa} \\
710 \mathrm{MPa}\end{array}$ & $\overline{0^{\times}} \mathrm{O}^{\times} 0^{\times}$ & 0.82 & $\begin{array}{l}710+0.82 \times 30 \\
=735(\mathrm{MPa})\end{array}$ \\
\hline 6.0 & $\begin{array}{l}740 \mathrm{MPa} \\
710 \mathrm{MPa} \\
680 \mathrm{MPa}\end{array}$ & $0^{x} \times 0^{x}$ & -0.42 & $\begin{array}{l}710-0.42 \times 30 \\
=697(\mathrm{MPa})\end{array}$ \\
\hline
\end{tabular}

Table 1: Fatigue test results and estimated bending fatigue limit stresses.

The permutations of $\mathrm{O}$ and $\mathrm{X}$, coefficient $\Delta$ determined on the basis of the relationship between $\Delta$ and the permutation recommended by Little [13] and the estimated bending fatigue limit stresses $\sigma_{w}$ for the five types of specimens are shown in Tab. 1 and Fig. 7. The estimated bending fatigue limit stresses $\sigma_{w}$ for the specimens with notch radii of 2.5, 3.0, 4.0, 5.0, and $6.0 \mathrm{~mm}$ are $787,765,753,735$, and $697 \mathrm{MPa}$, respectively. Since the bending fatigue limit stresses are expressed as the actual stresses at the critical point, they increased with decreasing notch radius with a more severe stress concentration. Therefore, although the bending fatigue limit stress increased with decreasing notch radius, as shown in Fig. 7. it does not mean that a sharper notch will increase the strength of the specimen. Fig. 8 shows the load $P_{w}$ corresponding to the results in Fig. 7, which indicates the load capacity of the specimen, and the nominal bending fatigue strengths $\sigma_{w n}$ given by the bending stress of the smooth specimen with the same section as the minimum section shape of the notched specimens under a load of $P_{m \text {. }}$ 
As shown in Fig. 8, a smaller radius or sharper notch with a more severe stress concentration decreases the bending load capacity. This corresponds to the common knowledge that the stress concentration reduces the fatigue strength of machine elements.

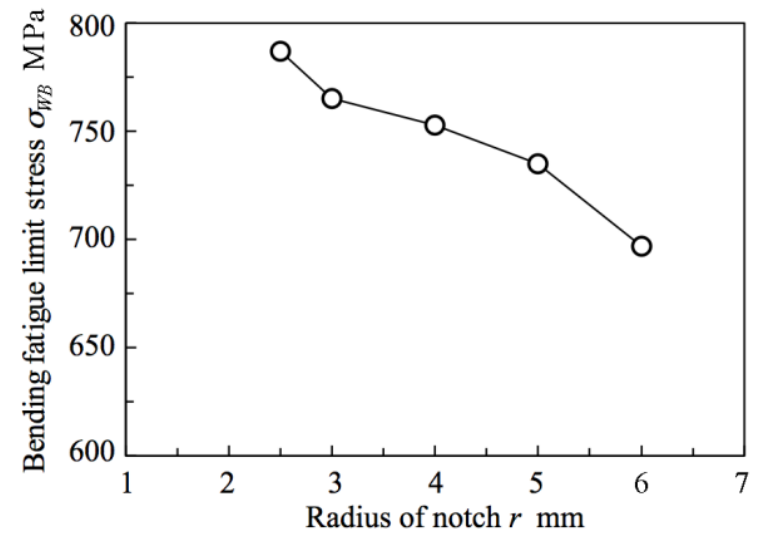

Figure 7: Bending fatigue limit stresses of the specimens with different notch radii.

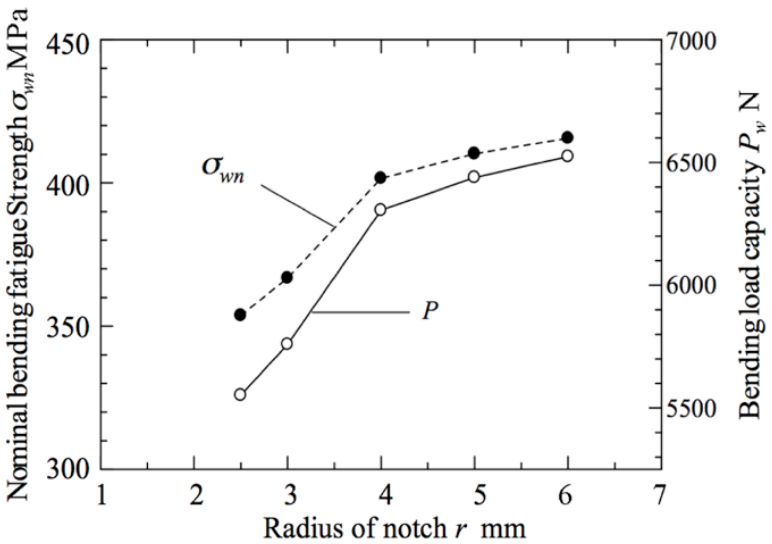

Figure 8: Nominal bending fatigue strengths and bending load capacities.

\section{ESTIMATION OF THE TENSION FATIGUE STRENGTH OF A SMOOTH SPECIMEN}

\section{Actual stress and its distribution in the depth direction from the critical point}

A $\mathrm{s}$ mentioned above, assuming that whether or not bending fatigue breakage occurs depends on the initiation of a surface fatigue crack, the criteria for the initiation of a fatigue crack can be used for bending fatigue strength design.

Considering that the initiated fatigue crack is very small, the region affecting the crack initiation should be restricted within a very small area; thus, the stress gradient at the critical point can be used as the main factor characterizing the distribution of the stress around the critical point. Consequently, the effect of the stress distribution on the bending fatigue strength may be evaluated by the stress gradient at the critical point. Referring to the research of Siebel [10], we focus on the gradient of the normal stress distribution in the depth direction at the critical point, as shown in Fig. 9, where the color bands show the stress distribution.

The stress gradient $g\left[\mathrm{~mm}^{-1}\right]$ along the depth direction ( $x$ direction) is defined by the following expressions:

$$
\sigma^{\prime}=\frac{\sigma}{\sigma_{0}}, \quad g=\left|\frac{d \sigma^{\prime}}{d x}\right|
$$

where $\sigma$ is the normal stress, namely the actual bending stress, perpendicular to the critical section, $\sigma_{0}$ is $\sigma$ at the critical point, $\sigma^{\prime}$ is the dimensionless stress, and $x$ is the depth below the critical point. The gradients at the critical point $g_{0}\left[\mathrm{~mm}^{-1}\right]$ are shown in Fig. 10, from which it is clear that a smaller notch radius, namely a more severe stress distribution, is accompanied by a higher gradient. The gradients were $0.848,0.800,0.688,0.598$, and $0.491 \mathrm{~mm}^{-1}$ for notch radii of $2.5,3.0$, $4.0,5.0$, and $6.0 \mathrm{~mm}$, respectively.

\section{Estimation of the tension fatigue strength of the smooth specimen}

We consider that the fatigue strength should be a shape-independent mechanical property that depends on the properties of the material such as the yield stress and hardness, and the surface qualities such as the roughness and texture at the critical point. Here, we call this fatigue strength the material fatigue strength. This material fatigue strength should be obtained for the smooth specimen (no stress concentration) and have no stress gradient (uniformly distributed stress, $g=0$ ). Siebel [10] compared the bending fatigue strength of a notched specimen $\sigma_{W}$ with the tension-compression (push-pull) fatigue strength $\sigma_{W 0}$ of a smooth specimen. We also consider that the fatigue strength of a smooth specimen under a uniformly distributed stress may be used as the material fatigue strength for bending fatigue strength design. 


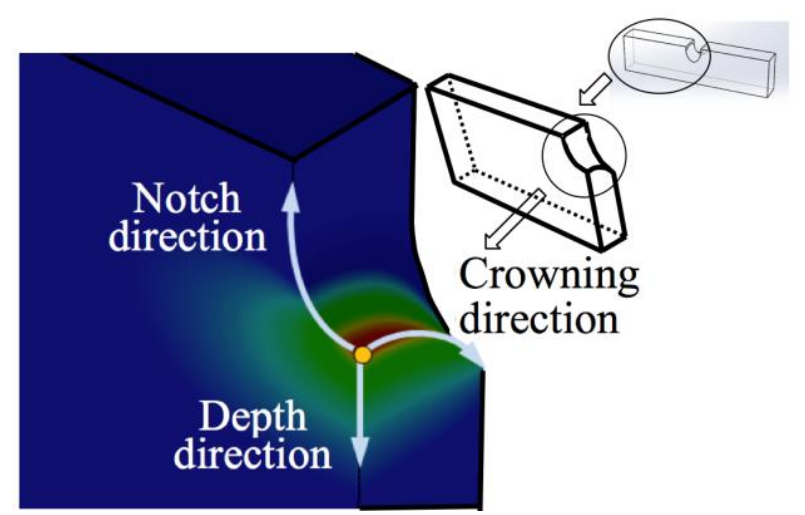

Figure 9: Stress distribution around the notch of a specimen.

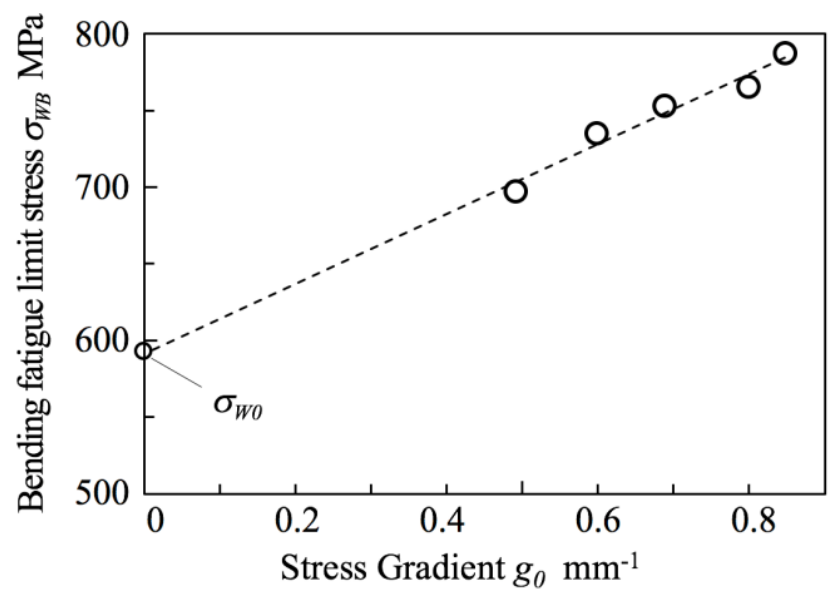

Figure 11: Extrapolation for tension fatigue strength

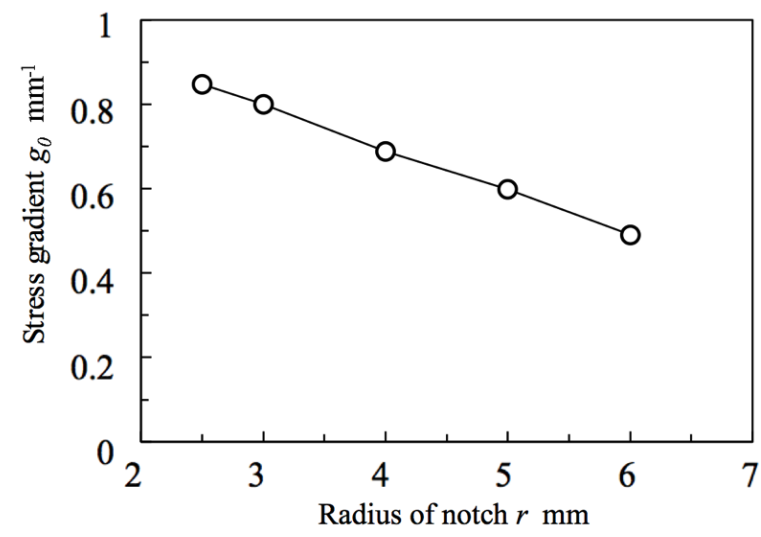

Figure 10: Stress gradient at the critical point.

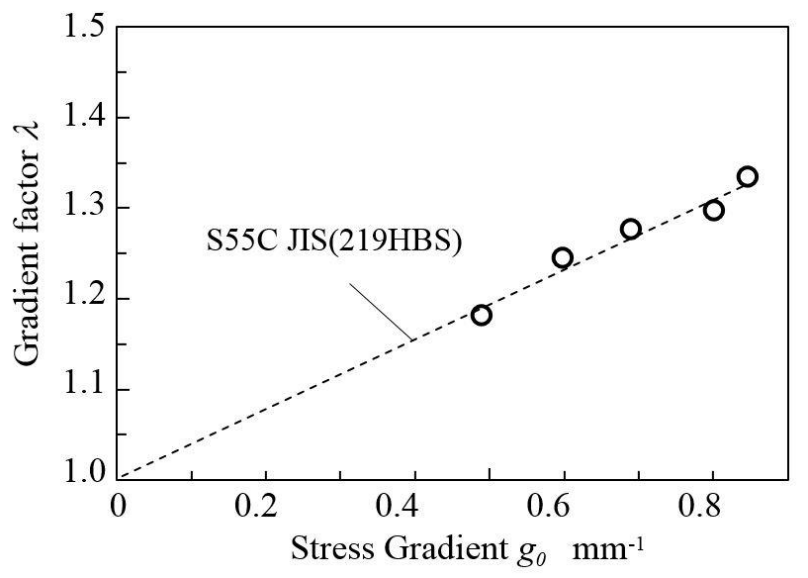

Figure 12: Gradient factor vs. stress gradient

Fig. 11 shows the relationship between the bending fatigue limit stress $\sigma_{w}$ and the stress gradient $g_{0}$, which indicates that the bending fatigue limit stress decreases almost linearly with decreasing stress gradient in the depth direction at the critical point. Along the horizontal axis in Fig. 11, a smaller gradient corresponds to a smoother specimen. Thus, $g_{0}=0$ corresponds to a smooth specimen under a pulsating tension load. The tension fatigue strength $\sigma_{W 0}$ was estimated by extrapolation using the experimental results of the notched specimens, and we obtained the value of 592MPa in Fig. 11 using the experimental results in Fig. 7. However, the appropriateness of the estimation of the tension fatigue strength should be investigated and discussed on the basis of many experiments. Here we only present an approach for the determination of the tension fatigue strength, which can used as the material fatigue strength for bending fatigue strength design. Through the use of the tension fatigue strength $\sigma_{W 0}$ as the material fatigue strength for bending fatigue strength design, the gradient factor $\lambda$, which is used to evaluate the effect of the stress distribution on the bending fatigue strength, can be defined as the ratio of the bending fatigue limit stress $\sigma_{w}$ to the tension fatigue strength $\sigma_{W 0}\left(\lambda=\sigma_{w} / \sigma_{W 0}\right)$. The gradient factors for the specimens used in this research increase progressively according to the increased gradients as shown in Fig. 12.

\section{Conceivable approach for general bending fatigue strength design}

Many further bending fatigue tests should be conducted using specimens with different shapes to confirm that the tension fatigue strength depends on the material properties and to clarify the relationship between the gradient factor and the stress gradient for different materials. A conceivable approach for general bending fatigue strength design applicable to machine components with a wide range of geometries is shown in Fig. 13. First, the actual stress $\sigma_{\max }$ and its gradient at the critical point $g_{0}$ are calculated by FEM analysis, then the gradient factor $\lambda$ is determined from the relationship between the gradient factor and the stress gradient. Next, the tension fatigue strength $\sigma_{W 0}$ is estimated for the material. The allowable actual stress $\sigma_{a}$, which is the limit bending stress for the designed machine component, is calculated as the product of the tension fatigue 
strength $\sigma_{W 0}$ and the gradient factor $\lambda$. The fatigue strength design is performed while ensuring that $\sigma_{\max }<\sigma_{a}$. In addition, the tension fatigue strength $\sigma_{W 0}$ depends not only on the material properties but also on the surface qualities as mentioned above. Since we used mirror-polished notches, this research does not deal with the effects of surface qualities on the tension fatigue strength, namely the material fatigue strength.

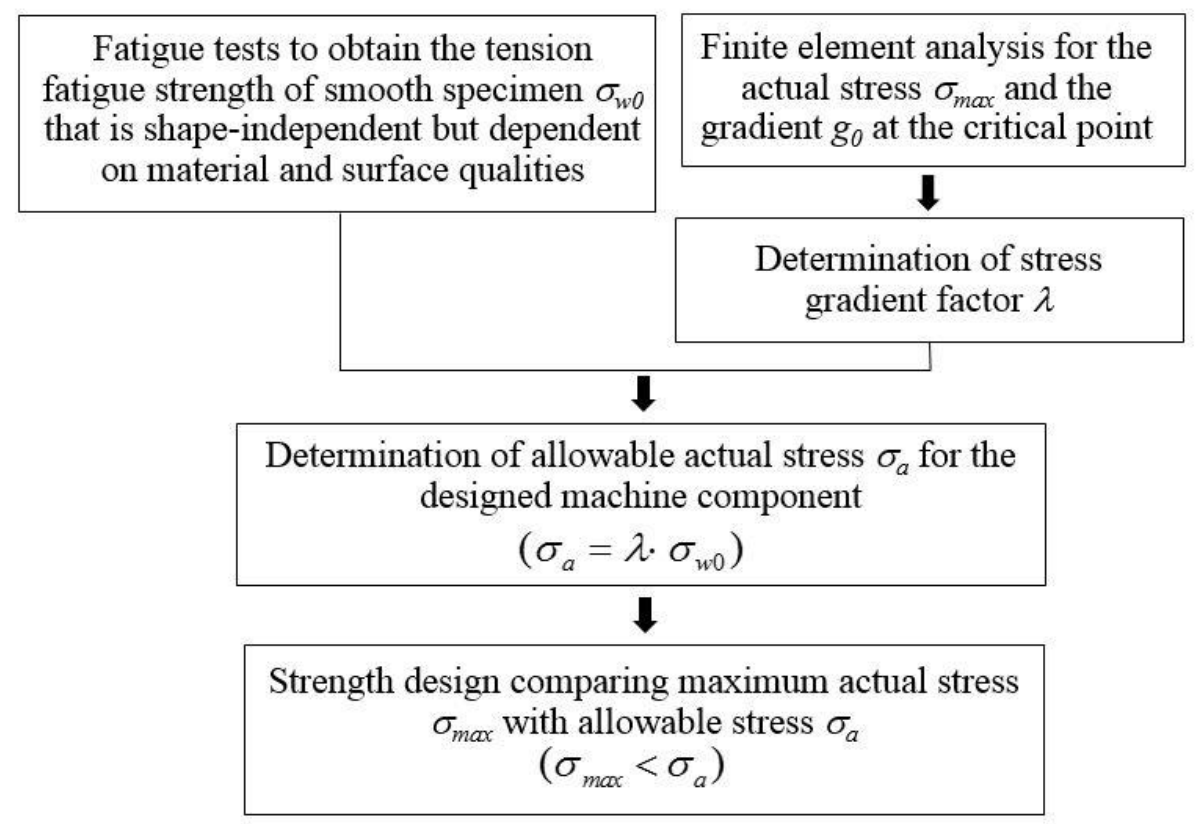

Figure 13: Conceivable general bending fatigue strength design method.

\section{CONCLUSIONS}

U nder the consideration that bending fatigue breakage depends on the initiation of a surface fatigue crack, the conditions for the initiation of a fatigue crack can be used as the criteria for bending fatigue strength design; whether or not the fatigue crack initiation depends on the maximum actual stress and its distribution at the critical point on the basis of fracture mechanics. In this study, the maximum stress and its gradient in the depth direction at the critical point were taken as the predominant factors affecting fatigue crack initiation. Three-point bending test pieces with crowned and round notches were used in fatigue experiments to obtain bending fatigue limit stresses, and we presented an approach to estimating the tension fatigue strength of a smooth specimen, which is the material fatigue strength used in general bending fatigue design. The main results obtained in this research are as follows.

1) If the fatigue strength is expressed as the actual stress at the critical point, the bending fatigue limit stress will be higher for a more severe stress concentration. In our experiments, a higher bending fatigue limit stress was obtained for a smaller notch radius.

2) The tension fatigue strength of a smooth specimen, which is the material fatigue strength used in bending fatigue strength design, was estimated by extrapolation using the experimental results of notched specimens.

3) A conceivable approach to general bending fatigue strength design applicable to machine components with a wide range of geometries is presented that uses the actual stress, stress gradient factor, and tension fatigue strength of a smooth specimen.

\section{REFERENCES}

[1] JSME, (1991). Strength Design for Gears (in Japanese), Technical Document, pp. 86-99.

[2] JSME, (1992). Fatigue Strength Design for Metals II (in Japanese), Technical Document, pp. 66-141.

[3] Nisitani H., (1968). Size effect on fatigue limit and the diverge point on the rotating bending tests for carbon steel, Transactions of the JSME (in Japanese), 34-259, pp. 371-382.

[4] Ohba, H., Murakami, Y. and Endo, T., (1983). Effects of an artificial small defect on the fatigue strength of notched 
specimen, Transactions of the JSME A (in Japanese), 49-444, pp. 901-910.

[5] Deng, G., Sakanashi, Y. and Nakanishi, T., (2009). A practical method for fatigue crack initiation detection using an ionsputtered film, Transaction of the ASME, Journal of Engineering Materials and Technology, 131-1 pp. 011007-1011007-6.

[6] Hammouda, M. M. and Miller, K. J., (1980). Prediction of fatigue lifetime of notched members, Fatigue of Engineering Materials and Structures, pp. 377-386.

[7] Nisitani H., (1977). Non-propagating crack (notched surface), Materials (in Japanese), 26-282, pp. 296-306.

[8] Tanaka, K. and Akiniwa, Y., (1987). A method for the prediction of fatigue limits of notched members, Transactions of the JSME A (in Japanese), 53-488, pp. 709-717.

[9] Kato, M., Deng, G., Inoue, K. and Takatsu, N., (1993). Evaluation of the strength of carburized spur gear teeth based on fracture mechanics, JSME International Journal, Series C, 36-2, pp. 233-240.

[10] Siebel, E. and Stieler, M., (1955). Ungleichformige Spannungsverteilung bei schwingender Beanspruchung, Verein Deutscher Ingenieure, Dusseldorf (in German), VDI-Z, 97-5, pp. 121-126.

[11] Inoue, K., Deng, G. and Kato, M., (1989). Evaluation of the strength of carburized spur gear teeth based on fracture mechanics (1st report, stress intensity factor considering the effect of residual stress distribution in the case), Transactions of the JSME C (in Japanese), 55-514, pp. 1488-1493.

[12] Akiniwa, Y., Tanaka, K. and Kinefuchi, M., (1989). Effect of microstructure on propagation and non-propagation of short fatigue cracks at notches, Materials (in Japanese), 38-434, pp. 1275-1281.

[13] Little, R. E., (1972). ASTM Spec. Tech. Publ., 5-11, p. 29.

[14] Jeong, B., Kato, M., Inoue, K. and Takatsu, N., (1992). The Bending Strength of Carburized Fine Module Gear Teeth: Carburizing Conditions and Their Effects on the Fatigue Strength, JSME International Journal, 35-1, pp. 136-141. 